\title{
Developing the Ecological Self: A Socially Engaged Art Project
}

\author{
Megan Delaney, $\mathrm{PhD}^{\mathrm{a}^{*}}$, Kimberly Callas, $\mathrm{MFA}^{\mathrm{b}}$, Sunanda Sharma ${ }^{\mathrm{c}}$ \\ ${ }^{a}$ Monmouth University, Department of Professional Counseling, West Long Branch, NJ \\ ${ }^{b}$ Monmouth University, Department of Art and Design, West Long Branch, $N J$ \\ ${ }^{c}$ Montclair State University, Department of Counseling, Montclair, NJ
}

*Corresponding Author: Megan Delaney, PhD, Monmouth University, Department of Professional Counseling, West Long Branch, NJ, USA

\begin{abstract}
Social practice is a growing method of change making as well as ways of engaging people in social connection and discourse (Schlemmer, 2017). Connection to nature improves human physical and mental health (Frumkin et al., 2017) as well as increases environmental stewardship (Reese, 2018). This qualitative study investigated the experiences of six undergraduate art students and seven adolescents after exposure to a nature-based socially engaged art project. Focus group and survey data revealed the undergraduate students' central domains include a lived experience through meaning making through socially engaged art and the adolescents' domains include the enjoyment of multidisciplinary/socially engaged learning. Both groups experienced a deeper connection to nature. Findings from this study highlight the ways that a socially engaged art project can influence the ecological stewardship of a diverse set of young people.
\end{abstract}

Keywords: socially-engaged art; nature-based art; ecotherapy; environmental stewardship

\section{INTRODUCTION}

Educators often search for ways to involve youth in experiences that can have a positive, long-term effect on development (Barnes, Cross \&Gresalfi, 2011). Research has found that creativity via art (Einarsdottir, Dockett \& Perry, 2009) and nature-based interventions are two way to engage children (Maller, Henderson-Wilson, \& Townsend, 2009). Research also indicates that involving youth in environmental causes helps to create an ecological identity, which can have long term benefits for the planet (Reese, 2018). Providing children, especially those with limited access to safe natural-places, experiences to explore and learn about the natural world is shown to increase their understanding and appreciation for the natural world (Asah et al., 2017) with the added benefits of improved mental and physical health (Frumkin et al., 2017). The purpose of this project was to study a novel curriculum, Discovering the Ecological Self (D-Eco-Self), a socially engaged art initiative designed for children to learn environmental stewardship through hands-on and creative methodology.

D-Eco-Self is a multi-institutional art project designed to foster environmental stewardship and create environmental leaders and social practice artists. This socially engaged art project addresses environmental issues with communities by exploring personal and universal nature-based symbols and patterns through research and art making. Discovering the Ecological Self serves to re-awaken our relationship with the world around us and create a deeper understanding of our role in nature as a participant in order to inspire a responsibility to care for our planet and other species. University professors from multiple disciplines, including the arts and hard sciences, teach afternoon workshops that include field investigations, group and individual research projects and art making. The process is to identify personal and culturally significant nature-based symbols, patterns, and images through contemplative art making practices, on-site field exploration and scholarly research. Participants identify a subject (tree, bird, ocean, etc.) and then research it for personal, scientific, cultural and historical background. From the research, participants create art works, eco-masks, and a narration that can be either scientific, poetic, mythical, mystical or all of the above. The participants speak the narration through their masks to give voice and vision to their ecological selves. The overarching goal of the D-Eco-Self project is to have all participants explore a deeper relationship with nature potentially discovering new understandings of themselves and their place in the universe. The broader goal of the project is to empower participants to become environmental advocates and stewards. 
The purpose of the following research is to a) examine the experiences of adolescents and undergraduate students who participate in the D-Eco-Self project as well as b) examine the process of socially engaged art on environmental stewardship in young people. Results from this qualitative study provides insight to the phenomenon of students participating in this project, especially how students make meaning of their experience and how this experience affects the participants' connection to nature. The research questions guiding this study include; What are the experiences of adolescent students and undergraduate art students who participated in the D-Eco-Self project? How do participants make meaning of this project? Does this experience, if at all, influence students' connection to nature and influence an ecological self? Does socially engaged art (SEA) as the method of transformation and/or delivery of the project, influence participants" "eco-self"?

\section{LITERATURE REVIEW}

\subsection{Socially Engaged Art}

Socially engaged art (SEA) is a practice within art education pedagogy with its roots in service learning and community arts (Schlemmer, 2017). SEA is an exercise in collective meaning making (Schrag, 2018) and it engages both the artist and students through a transformative egalitarian relationship (Taylor, 2002). This art form inspires civic engagement, social change, communication, creative problem solving, and self-reflection (Schlemmer, Carpenter \& Hitchcock, 2017). Art is meaningful for individual self-expression; however, socially engaged art is powerful for education and creating a collective critical conscious for participants. Froggett, Roy, Little and Whitaker's (2011) report of visual art and social engagement offers insight into the ways socially engaged art offers transformation including extending the capacity for symbolism; offering a voice and a sense of authenticity and connection providing "a third object between themselves and others that can be shared" (p. 92). SEA projects identify grave injustices in local communities and across the world (global water crisis, climate change, food scarcity, etc.), but make them more approachable and encourage connection, collaboration, communication, and creativity among the artist and the participants (Schlemmer et al., 2017). The dialogical exchanges and participatory nature of SEA are the agents of change (Schrag, 2018; Taylor, 2002), and the experience itself serves as a learning resource for students (Taylor, 2002). SEA projects rely on the artist to initiate and facilitate the learning process, but ultimately both parties construct the creative experience together and grow in response to the exchange (Hyungsook, 2014).

\subsection{Benefits of Nature}

Research links time in nature with well-being, mental health, cognitive function (Hanscom\&Louv, 2016), self-concept (Reese, 2018), reduced stress and depression (Morrison \& Gore, 2010), and restoration from mental fatigue (Brymer, Cuddihy, \& Sharma-Brymer, 2010). As such, nature-based activities support youth and adults to improve physical and mental health (Bratman et al., 2015; Frumkin et al., 2017). Most research on the educational value of learning in nature appears in $\mathrm{K}-12$ contexts (Barnes, Cross, \&Gresalfi, 2011). Researchers found positive relationships between exposure to natural settings and students' cognitive abilities, focus (Li \& Sullivan, 2016), engagement (Rios \& Brewer, 2014), enthusiasm for learning (Blair, 2010), and academic performance (Chawla, 2015). With growing evidence that nature-based learning positively affects child development, there is a call for more evidence-based learning experiences that highlight this connection (Hanscom\&Louv, 2016).

\subsection{Ecological Identity/Environmental Stewardship}

Ecological identity is one's connection to and attitude toward the natural world and environment (Wilson, 1996). Many factors that influence this connection including cultural beliefs and practices toward the environment, safe access to natural spaces, and personal experiences within the natural world (Wilson, 1996). Positive experiences in nature during childhood proves critical in the development of an ecological self and positive connection to nature (Reese, 2018). One's ecological identity evolves over time, but does not develop in isolation (Wilson,1995). Connection to the natural world and the development of an ecological identity is also linked to proximity to safe natural play areas. Children, most often poor, children of color, living in urban areas, do not always have safe access to green space (McCormick, 2017). Many children no longer have the freedom to roam wild and explore their local environment (Loebach\& Gilliland, 2016). Understanding the importance of the natural world for planetary health, many researchers and educators are exploring ways to reconnect children to nature as to ensure that the future generation has a developed environmental stewardship (Reese, 2018). 


\subsection{Purpose of the Study}

This qualitative project involved two sample groups, adolescents from an economically marginalized urban community and undergraduate students enrolled in an undergraduate art class at a mid-sized University in the United States. Using focus group and survey findings, the purpose of this study is to more fully understand how both groups experience this nature-based socially engaged-art project. Accordingly, the guiding questions for this study include: (1) how do participants make meaning of their experiences in Discovering the Ecological Self? and (2) how does this socially engaged art project influence participants connection to nature or "eco-self"?

\section{Method}

The selected method for the study was phenomenological inquiry, a method grounded in a robust philosophical history intended to explore the lived experience of participants (Hays \& Singh, 2012). Using a phenomenological approach, researchers attempt to get to an understanding of phenomenon, or that being studied, in order to obtain descriptive and personal accounts of how participants make sense of their experience (Moustakas, 1994). The researchers employed several guidelines founded in phenomenological research. These include designing the research questions around the livedexperience of the participants, being aware and avoiding researcher assumptions as best as possible, analyzing data using a phenomenological framework including reviewing for commonalities and variations and reflecting essential themes, and balancing the content of the research individually and as a whole (Balkin\& Kleist, 2017).

\subsection{Participants}

This study used purposeful sampling. Participants include adolescents and undergraduate art students in the D-Eco-Self project. The adolescents are from a local youth-ministry program designed to provide economically marginalized students with after-school activities. The study includes seven adolescents, one boy and six girls, mean age of 12.6, five identified as Black and two Hispanic. This study includes six undergraduate art students, all female, mean age of 20.7, all identified as white. With IRB approval, parental consent and assent forms were obtained from all adolescent parents and students; consent forms were obtained from the undergraduate art students.

\subsection{Procedures}

This qualitative study meant to gauge participants' connection to the natural world as a result in participation in this project. The first author, with the help of the graduate assistant, conducted separate semi-structured focus groups with the adolescent and undergraduate students at the end of the program. The focus group lasted 45 to 60 minutes respectively and explored the participants overall experience in the program, probing for deeper information on participants strongest memories within the natural world as well as their individual processes in the art project. Students were also asked to personally reflect on their experiences in the program.

\subsection{Analysis}

Qualitative data from the two focus groups were transcribed and read by the researcher on multiple occasions. Using focus group and personal reflection data, a list of themes was generated as evidenced by the data (Balkin\& Kleist, 2016) in order to understand and make sense of participants' voices. Qualitative inquiry through a phenomenological approach explored how students made meaning of their work during the project. A sense of meaning correlates with many helpful factors, especially during adolescence, including emotional health, overall well-being and engagement in academic work (Einarsdottir, Dockett \& Perry, 2009). In an effort to enhance the trustworthiness of this study, the researcher engaged a critical reflection process specific to their own social identities and positionalities (Hays \& Singh, 2012). As such, the researcher examined their own identities, biases, and positionalities throughout the processes.

\section{Results}

From the adolescent qualitative data, two domains emerged: Enjoyment of Multidisciplinary/Socially Engaged Learning and a Deeper Connection to Nature. The adolescents overwhelmingly agreed that the socially engaged and interactive approach to learning about the material allowed them to engage more deeply with the subject matter. Many commented on how they learned things about their neighborhood and local ecosystem that they hadn't learned (or recalled) from traditional instruction. 
[This project was] exciting; different; fun; new. I mean, I like never did this stuff before, they don't teach you this stuff in school. [Multidisciplinary/Socially Engaged Learning]

The students particularly enjoyed combining art with the information they learned about the natural world. They appreciated the process of making their faces into masks and using the 3-D printer to produce the masks [Figure 1]. They found enjoyment and connected with being able to use art to express themselves through their masks

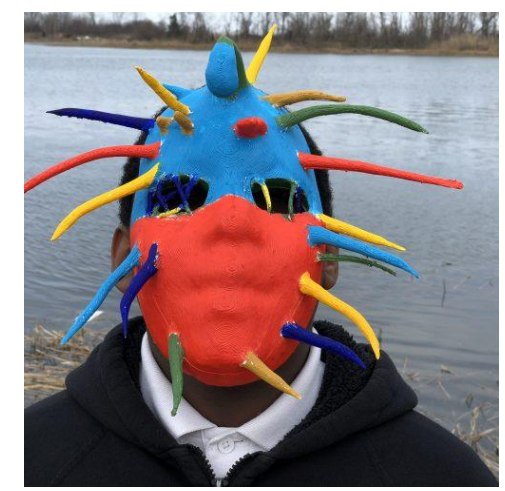

Figure1. Youth with Eco-Portrait Mask Angler Fish, 3D Print, PLA Bio Filament and Acrylic Paint, 10" $x 8$ " $x$ 4", 2018, Photography by second author.

[This project] open our minds about how art and nature... are connected. [Multidisciplinary/Socially Engaged Learning]

The adolescents also appreciated developing a deeper connection to nature, especially in their local beach community. In particular, the adolescents enjoyed going on a boat ride at the ocean [Figure 2]. For many, this was their first time on a boat. During the discussion, many expressed fear and joy about being on the water and enjoyed seeing all the different fish and fauna. Some reflected about their own connection to the ocean.

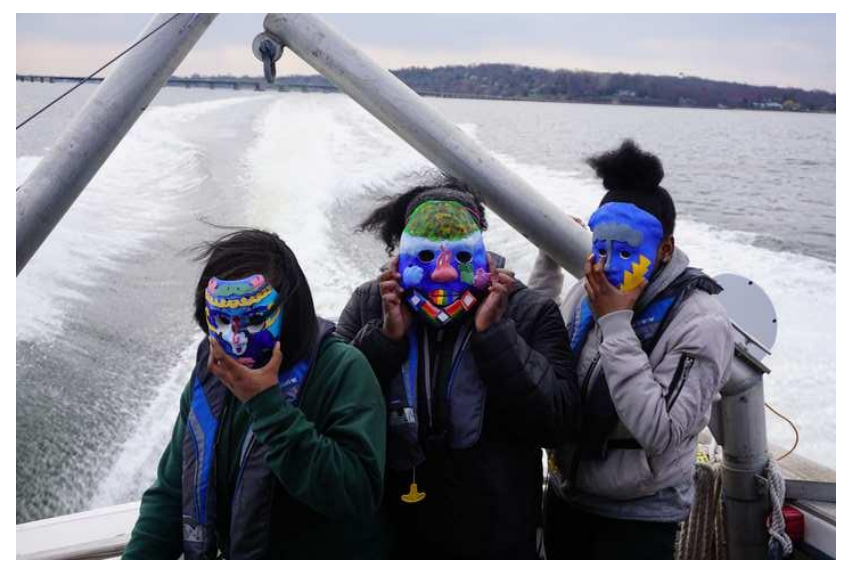

Figure2. Adolescent participants take a boat ride with their new mask creations. Photography by Karl Vilacoba used with permission.

What the ocean means to me is peace and stability because to me the ocean is a very stable place for me to go. [Deeper Connection to Nature]

Many adolescents commented on how the project made them reflect on their own individual as well as the collective contribution to caring for the environment.

[This experience has made me think differently about] how valuable nature is and how we have to stop hurting it.

I can be an example [to] other people and show them how they can make a change too. I will be the change!

I'll take care of nature better. I didn't realize how much we have an impact on it.

[This project helped me in] realizing how valuable, like how valuable life is. [Deeper Connection to Nature] 
From the undergraduate student qualitative data, two domains emerged: Meaning Making through Socially Engaged Art and a Deeper Connection to Nature. Students overwhelmingly valued the intersectionality of the natural world within the artistic process [Figure 3]. The combination of art and science instruction provided the participants a well-rounded experience. Furthermore, they saw the direct impact that this program had on the students.

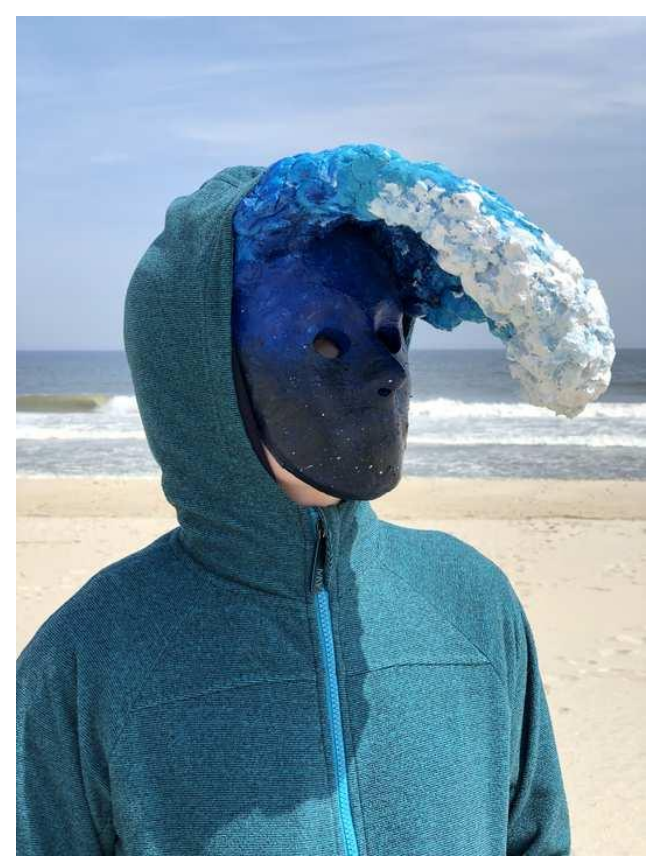

Figure3. Student with Eco-Portrait Mask Ocean Wave, 3D Printed Mask, PLA Filament, Acrylic, Spray Foam, 10 " X 14 " X 3.5”, Photography by second author.

Personally, this was a wonderful experience to have because we worked so much with different departments outside of Art. I loved being able to work within the community and make an impact on the [adolescent] students' ideas about nature. I think we also changed their ideas about art and what it means to be an artist. The installation also showed the students a level of professionalism that comes with being an artist. [Meaning Making through Socially Engaged Art]

This also inspired the undergraduate students to think beyond the individual artistic process to ways in which art engagement can involve the community.

I honestly love this program that we're doing so much because we're teaching these kids how important it is that they, not only, to relate to nature in its physical sense biologically but also understanding how they can relate on an artistic level.

I'm definitely going to be working with kids and I definitely want to structure my lessons around nature. [Meaning Making through Socially Engaged Art]

Including ways that the undergraduate students can incorporate these techniques into future artistic and educational endeavors.

Art, science, and social practice can be related in magnificent and impactful ways. Art is not a medium, it is a vessel. [Meaning Making through Socially Engaged Art]

This project can relate to all of us and is not just limited to this classroom and the workshop. Working together with others from different disciplines, age groups, and walks of life enhances the project greatly. It is works like these that leave a lasting impression on all who were a part of it. [Meaning Making through Socially Engaged Art]

Undergraduate students also reflected on the ways in which the project impacted their own deeper connection and reflection about their personal connections to nature.

[The ocean means] balance and beauty and peace and power and just life itself...

We need to conserve nature and make sure that we're keeping it safe for the generations that follow us. [Deeper Connection to Nature] 
As an artist, I think it is important to incorporate nature into my work. [Deeper Connection to Nature]

[Re: to making their own masks] I think it was really different to sit and think about an aspect of nature that we personally connect with, I don't think it's a normal everyday thought that you have...so I really thought about why I identified with a specific part of nature... [Deeper Connection to Nature].

\section{DISCUSSION}

Socially engaged practices involve students at a deeper level by providing socially engaged and often multi-sensory ways of engaging in a subject matter (Roman, 2018). The purpose of the D-Eco-Self, a socially engaged art project, is to encourage environmental stewardship by restoring our personal relationship with nature. Combining art and science, the project provided an opportunity for adolescents to get exposure to a college campus; engage with undergraduate students; gain experience in multidisciplinary ways of content instruction; learn about local ecosystems, and express themselves through art. Furthermore, this type of socially engaged, multi-disciplinary, interactive, creative and empirically based project can help create environmental stewards for generations to come.

Overall, both the adolescent and undergraduate students stated that the D-Eco-Self project was an informative, thought-provoking and valuable experience. Through qualitative data, both groups expressed a deeper connection to the natural world after participating in the project. Many participants spoke directly of ways that they, individually, felt a deeper commitment to protect the natural world. Many of the adolescent participants learned about their local ecosystems, expressing deeper connections and appreciation for their natural world in their surrounding communities. Environmental stewardship requires a sense of connection to an ecosystem (Kahn and Hasbach, 2012). D-Eco-Self shows promising results that this particular project is one way at inspiring young people in the ongoing environmental cause.

The findings from this study also support projects that are benefits to undergraduate students through interdisciplinary and social engaged practices in education. The undergraduate art students were overwhelming enthusiastic about their participation in the project. Many indicated that this experience not only influenced how they might engage with children in the future but also how they see themselves as artists. Several students stated that they felt more deeply connected with the natural world and as such would incorporate nature elements in future art projects. This project allowed one student to "think of creativity in a different way" and many echoed the sentiment. In sum, the D-EcoSelf project engaged participants, at all ages and developmental stages, in a creative and expressive learning experience growing content knowledge in both arenas of science and art. It also created, in all participants, a richer understanding of their individual ecological self.

\section{Limitations AND FUTURE RESEARCH}

The purpose of this study is to provide pilot data in order to evaluate the lived-experiences as well as any change in connection to nature to both adolescent and undergraduate students participating in this socially engaged art project. These preliminary findings supported the hypothesis that the D-Eco-Self project engages students in activities that create a sense of environmental stewardship. The findings of this study is limited by the sample size and as such, no generalizable implications can be made. Replicate studies with larger sample size would provide further information about the broader implications of the D-Eco-Self project as well as other similar, multidisciplinary programs. It is important to point out that the college students all identified as White and the adolescent participants identified as Black or Latino/a. The researchers did not probe on this difference but, in hindsight and for future research, it would be important to discuss how race/ethnicity influences the experience as well as acknowledge different levels of privilege/access to the natural world.

\section{CONCLUSION}

Finding from this study support creative approaches to engaging young people in ways to connect to the natural world and adds to a growing body of literature in inventive approaches to teaching and engaging in science (Küçük Demir \& Isleyen, 2015). The larger implication of this study indicate that multifaceted approaches to teaching can excite students who may not otherwise be interested in a subject. In the case of D-Eco-Self, the project creates a sense of connection in participants to their local environment and a sense of responsibility for the natural world. D-Eco-Self is one initiative in a sea of many opportunities to bring together diverse experiences to solving the environmental crisis and inspiring a new generation of environmental stewards. 


\section{ACKNOWLEDGEMENT}

The researchers would like to acknowledge the Urban Coast Institute (UCI) at Monmouth University for ongoing support of this project.

\section{REFERENCES}

[1] Asah, S. T., Bengston, D. N., Westphal, L. M., \&Gowan, C. H. (2017). Mechanisms of children's exposure to nature: Predicting adulthood environmental citizenship and commitment to nature-based activities. Environment and Behavior, 50, 807-836.

[2] Balkin, R. S., \& Kleist, D. M. (2016). Counseling research: A practitioner-scholar approach. John Wiley $\&$ Sons.

[3] Barnes, J., Cross, D., \&Gresalfi, M. S. (2011). When does an opportunity become an opportunity? Unpacking classroom practice through the lens of ecological psychology. Educational Studies in Mathematics, 80, 249-267.

[4] Blair, D. (2010). The child in the garden: An evaluative review of the benefits of school gardening. Journal of Environmental Education, 40(2), 15-38.

[5] Bratman, G. N., Hamilton, J. P., Hahn, K. S., Daily, G. C., \& Gross, J. J. (2015). Nature experience reduces rumination and subgenual prefrontal cortex activation. Proceedings of the National Academy of Sciences of the United States of America, 112, 8567-8572. doi:10.1073/pnas.1510459112.

[6] Brymer, E., Cuddihy, T. F., \& Sharma-Brymer, V. (2010). The role of nature-based experiences in the development and maintenance of wellness. Asia-Pacific Journal of Health, Sport and Physical Education, 1, 21-27. doi: 10.1080/18377122.2010.9730328.

[7] Chawla, L. (2015). Benefits of nature contact for children. Journal of Planning Literature, 30,309-317.

[8] Einarsdottir, J., Dockett, S., \& Perry, B. (2009). Making meaning: Children's perspectives expressed through drawings. Early child development and care, 179(2), 217-232.

[9] Froggett, L., Roy, A., Little, R., \& Whitaker, L. (2011). New model visual arts organisations and public engagement. Retrieved from University of Central Lancashire: http://clok.uclan. ac.uk.

[10] Frumkin, H., Bratman, G. N., Breslow, S. J., Cochran, B., Kahn, P. H., Jr., Lawler, J. J., . . Wood, S. A. (2017). Nature contact and human health: A research agenda. Environmental Health Perspectives, 125(7). doi:10.1289/EHP1663.

[11] Hays, D. G., \& Singh, A. A. (2012). Qualitative research paradigms and traditions. Qualitative inquiry in clinical and educational settings, 32-66.

[12] Hanscom, A. J., \&Louv, R. (2016). Balanced and barefoot: How unrestricted outdoor play makes for strong, confident, and capable children. New Harbor.

[13] Hyungsook, K. (2014). Socially engaged art practice and character education: Understanding others through visual art. International Journal of Education through Art, 10(1), 55-69. doi:10.1386/eta.10.1.55_1.

[14] Kahn, P.H. \& Hasbach, P.H. (2012). The rediscovery of the wild. Massachusetts Institute of Technology.

[15] KüçükDemir, B., \&Isleyen, T. (2015). The effects of argumentation based science learning approach on creative thinking skills of students. Educational Research Quarterly, 39(1), 49.

[16] Li, D., \& Sullivan, W. C. (2016). Impact of views to school landscapes on recovery from stress and mental fatigue. Landscape and Urban Planning, 148, 149-158.

[17] Maller, C., Henderson-Wilson, C., \& Townsend, M. (2009). Rediscovering nature in everyday settings: Or how to create healthy environments and healthy people. EcoHealth, 6(4), 553-556.

[18] McCormick, R. (2017). Does access to green space impact the mental well-being of children: A systematic review. Journal of Pediatric Nursing, 37, 3-7. doi:10.1016/j.pedn.2017.08.027

[19] Morrison, C., \& Gore, H. (2010). Relationship between excessive internet use and depression: A questionnaire-based study of 1,319 young people and adults. Psychopathology, 43,121-126.

[20] Moustakas, C. (1994). Phenomenological research methods. Sage.

[21] Reese, R. F. (2018). EcoWellness: Contextualizing nature connection in traditional clinical and educational settings to foster positive childhood outcomes. Ecopsychology, 10(4), 289-300. doi:10. 1089/eco.2018.0031.

[22] Rios, J. M., \& Brewer, J. (2014). Outdoor education and science achievement. Applied Environmental Education and Communication, 13, 234-240.

[23] Schlemmer, R.H., Carpenter, B.S., II, Hitchcock, E. (2017). Socially engaged art education: Practices, processes, and possibilities. Art Education, 70(4), 56-59. doi:10.1080/00043125.2017.1317564. 
[24] Schrag, A. (2018). Non-visual aesthetics: Seeing the world with our bodies. Visual Culture in Britain, 19(2), 216-236. doi:10.1080/14714787.2018.1465845

[25] Taylor, P.G. (2002). Service-learning as postmodern art and pedagogy. Studies in Art Education, 43(2), 124-140.

[26] Wilson, R.A. (1996). The development of the ecological self. Early Childhood Education Journal, 24(2), 121-123.

\section{AUTHORS' BIOGRAPHY}

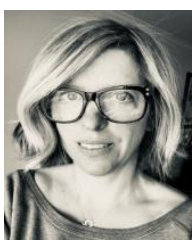

Megan Delaney, PhD, LPC is an Assistant Professor in the Department of Professional Counseling at Monmouth University, in West Long Branch, NJ. Her recent book, Nature is nurture: Counseling and the natural world (2020) combines research and practical application for counselors to infuse nature as a therapeutic partner. She teaches applied ecotherapy courses at Monmouth. She also has a private ecotherapy practice, Therapy Without Walls, LLC and is a regular contributor to Psychology Today. Dr. Delaney's research agenda focuses on clinical outcomes in Ecotherapy as well as student experiences in nature-based counseling curriculum.

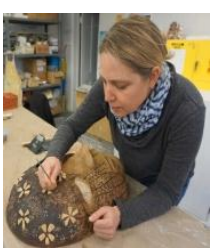

Kimberly Callas, is a new media artist, sculptor, and the lead artist of the Social Practice project Discovering the Ecological Self. She is currently the Artist-inResidence for the Urban Coast Institute and an Assistant Professor of Art at Monmouth University, in West Long Branch, NJ. Her work has been exhibited internationally in galleries and museums and has received national and international grants and awards. Recent grants include a Pollination Project Grant, an Urban Coast Institute Grant, and a Monmouth University Summer Faculty Fellowship. Recent exhibits include the 2019 International New Media Exhibit at the CICA Museum in South Korea, Summer Exhibition at Flowers Gallery in New York City, $9 \times 12$ at Dual Galleria in Budapest, Hungary and Crossing Boundaries: Art and the Future of Energy at The Pensacola Museum of Art, Pensacola, FL. Her work has been published in Post Human, New Media Art 2020 by CICA Press and has appeared in the Huffington Post and Art New England. Callas received her MFA from the New York Academy of Art and her BFA from Stamps School of Art at the University of Michigan.

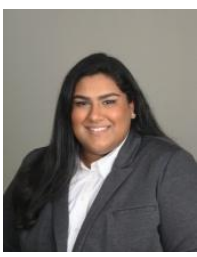

Sunanda "Suni" Sharma, is a second year doctoral student and research fellow in the Counseling PhD program at Montclair State University. Suni is currently a licensed associate counselor (LAC) in the state of New Jersey and nationally certified counselor (NCC). Suni received her master's in Clinical Mental Health Counseling from Monmouth University in 2019 and completed specialized coursework in substance use. Suni served as a 2018 NBCC Minority Addictions Fellow and has clinical experience working in a co-occurring program. Suni is presently the president-elect of Montclair's Chi Sigma Iota chapter, Chi Sigma Mu. Suni's research interests include substance use prevention, South Asian women survivors of domestic violence, and counseling ethics.

Citation: Megan Delaney, PhD, et.al. "Developing the Ecological Self: A Socially Engaged Art Project" International Journal of Humanities Social Sciences and Education (IJHSSE), vol 8, no. 2, 2021, pp. 189-196. doi: https://doi.org/10.20431/2349-0381.0802019.

Copyright: (0) 2021 Authors. This is an open-access article distributed under the terms of the Creative Commons Attribution License, which permits unrestricted use, distribution, and reproduction in any medium, provided the original author and source are credited. 